\section{Neon color spreading, partially delineated borders, and the formation of illusory contours}

\author{
R. H. DAY \\ Monash University, Clayton, Victoria, Australia
}

Day and Jory (1980) and Day and Kasperczyk (1983a, 1983b) have proposed that illusory contours, apparent edges in physically uniform regions (Ehrenstein, 1942; Gregory, 1972; Kanizsa, 1955; Schumann, 1904), are due primarily to the spread of induced contrast to partially delineated borders. Brightness (or darkness) is enhanced by simultaneous and line-end contrast and reduced by assimilation of brightness. The spread of one or more of these forms of contrast to borders delineated by features such as fragments of real edge, ends of lines, and dots give rise to illusory contours coincident with the borders.

In these terms, it can be expected that the strength of illusory contours will be greater when enhanced brightness (or darkness) spreads to one side of a partially delineated border and reduced brightness (or darkness) to the other. This is probably so with the well-known Kanizsa triangle (Kanizsa, 1955, 1976, 1979), in which simultaneous and line-end contrasts spread inside the partially delineated triangle and assimilation of brightness outside it (Day \& Jory, 1978). Day and Kasperczyk (1983a) have also argued that apparent depth due to overlay or other stimulus features correlated with depth serve to render partially delineated borders more perceptually salient and the coincident illusory contours consequently stronger.

An illusory color effect, "neon color spreading," has been described by van Tuijl (1975). The effect occurs, for example, when, in a lattice pattern of black 5-mm squares, sections of the black lines are replaced by red lines, which together form an embedded figure. The red coloration then appears to spread out around the colored elements into the adjacent squares to form a larger desaturated red figure. If, for example, the figure is roughly circular, the observer has a strong impression of a lattice with a desaturated "misty" red circle that appears to be projected onto it or is floating above its surface.

The effect has been investigated in detail by van Tuijl and his associates (van Tuijl \& de Weert, 1979; van Tuijl \& Leeuwenberg, 1979) and by Redies and Spillman (1981). The latter generated the effect in the Ehrenstein radiating-line figure (Ehrenstein,

The author's mailing address is: Department of Psychology, Monash University, Clayton, Victoria 3168, Australia.

1942) by connecting the arms through the center with either collinear colored or lighter lines. They showed that the effect is not due to either chromatic aberration or eye movements and does not occur with dichoptic presentation of the black and colored lines.

Like assimilation of brightness and color (Helson, 1943; Helson \& Joy, 1962; Helson \& Rohles, 1959; Newhall, 1942; von Bezold, 1876), the brightness and color of the neon effect tend towards that of the inducing elements. In van Tuijl's (1975) demonstrations, the region immediately surrounding the colored elements is tinged with the same color. Similarly, if the colored elements are replaced by gray elements, as in Redies and Spillman's (1981) experiments, the surrounding region is tinged with gray. The latter effect is evident in Figure $1 \mathrm{~A}$ in a variant of one of van Tuijl's patterns. In phenomenological terms, there is a misty light gray diamond that appears as if it were projected onto the lattice by an outside source.

Neon color spreading may be identical with assimilation of brightness and color. Varin (1971) and Ware (1980) made the open sectors and parts of the outline triangle in the Kanizsa figure colored or light gray. The outcome was, respectively, a colored and a light gray triangle, the illusory contours of which were coincident with its partially delineated borders. Ware (1980) described the effect with light gray sectors and lines as a "misty, bright triangle which seems to stand in front of and overlap three black disks and an outline triangle" (p. 103). The illusory contours are clearly in evidence along the partially delineated borders of the triangle. No such clear contours are evident in Figure 1A; the gray simply spreads to fill the adjacent squares, with the gray appearing to fade outward from the gray elements. It is presumably this fading that gives the diamond an indefinite edge. The question of the possible identity of the neon effect with assimilation is taken up below.

It is suggested that the absence of clear illusory contours in Figure $1 \mathrm{~A}$ is due to the lack of any par-

A

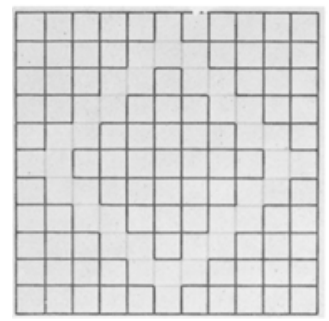

Figure 1. (A) A version of the van Tuijl (1975) lattice figure in which "neon spreading"' is observable on either side of the gray Hnes. (B) Restriction of neon spreading by partially delineated contours and the formation of coincident illusory contours. 
tially delineated borders along which the contours can form, as in Figure 2. Without such borders the neon effect generated by gray or colored elements merely spreads outwards, fading with increasing distance from the latter. If this suggestion is correct, then neon spreading of color or brightness affords a simple and effective means of testing the hypothesis that illusory contours derive from the spread of induced contrast to partially delineated borders (Day \& Jory, 1978; Day \& Kasperczyk, 1983a, 1983b). It can be expected that if a partially delineated border is added to Figure $1 \mathrm{~A}$, the gray will spread to the borders to form coincident illusory contours.

That this expectation is realized can be seen in Figure $1 B$, in which black dots have been placed at the midpoints of the squares on either side of each gray element. The outcome is a gray diamond with sharp illusory contours along the borders partially delineated by the dots. It is clear that the diffuse spreading of the gray has been arrested by the inside and outside borders of the diamond defined by the regularly spaced dots. Additional observations have shown that essentially the same outcome obtains with red elements.

Earlier, Day and Jory (1980) showed that line-end contrast (Day \& Jory, 1978; Frisby \& Clatworthy, 1975; Kennedy, 1979) generated in a cross-like figure (Figure 3A) devised by Koffka (1935) spreads to the partially delineated borders of a central square, diamond, or circle. The observations made with Figures $1 \mathrm{~A}$ and $1 \mathrm{~B}$ indicate that neon spreading can also



Figure 2. Ware's (1971) modification of Kanizan's triangle pattern in which the gray sectors and lines result in an apparent, "misty"' triangle with illusory contours. Ware's figure was derived from one by Varin (1971) in which the sectors and lines forming parts of the triangle were colored.
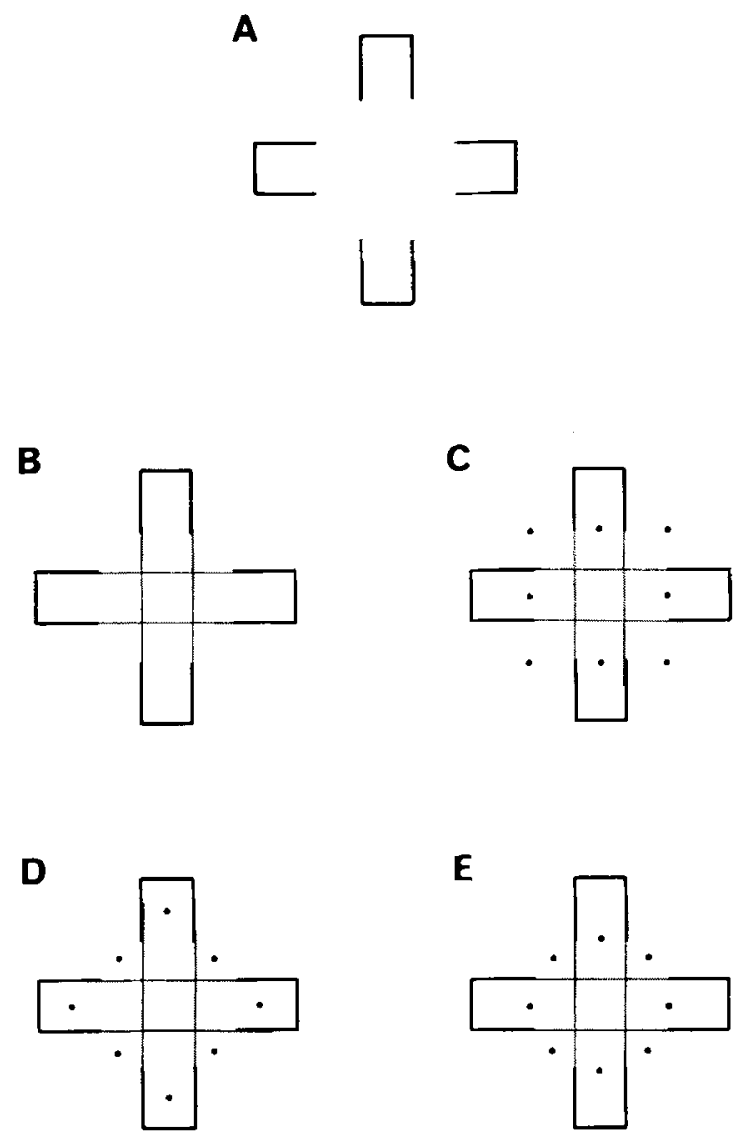

Figure 3. (A) The Kohler cross figure in which line-end contrast is generated and spreads in the central region. (B) Neon spreading in the central region with the addition of gray connecting lines. (C, D, and E) Restriction of neon spreading to a partially delineated square, diamond, and circle, respectively.

be expected to spread to the borders of the same figures. Neon spreading was generated in the Koffka figure by completing the black lines forming the arms of the cross with gray lines, as shown in Figure 3B. As can be seen, the typical neon brightness effect occurs. In Figures 3C, 3D, and 3E, dots are added to form, respectively, a square, a diamond, and a circle. That illusory contours coincident with the partially delineated contours of these figures are present is obvious from inspection of these figures. Again, it can be noted that essentially the same outcome occurred with red connecting lines.

What can be concluded from these observations? First, the occurrence of illusory contours in Figure $1 \mathrm{~B}$ and Figures $3 \mathrm{C}, 3 \mathrm{D}$, and $3 \mathrm{E}$ attest again to the central role played by partially delineated borders in the formation of illusory contours in physically uniform regions. Without such delineation, the neon brightness or color effects seem merely to spread out from the elements that induce them, as in Figures $1 \mathrm{~A}$ and $3 A$. This seems to be as much the case with neon spreading (Figure 1A) as it is with line-end contrast 
(Day \& Jory, 1980). Second, it seems reasonable to suppose that neon spreading is a special case of the assimilation of brightness and color first reported by Rood (1879) and von Bezold (1876). Ware (1980) generally subscribes to this view. In van Tuijl's (1975) patterns, it appears that the peculiar indefinitiveness of edges and the appearance of a figure "floating" above a pattern derive in large part from the absence of elements that restrict the spreading of the induced effect. The absence of such elements results in a fading of the induced effects, which, in turn, results in edge indefinitiveness and the floating appearance of the figure. However, it should be noted that Redies and Spillman (1981) claim that there are differences between neon spreading and assimilation. Whether these are fundamental or superficial is yet to be firmly established.

In summary, the observations made here of what van Tuijl (1975) has called neon spreading implicate both induced brightness and color, on the one hand, and partially delineated borders, on the other, as conditions for the formation of illusory contours. Without the borders, the induced effects tend to spread out to produce a poorly defined region of altered color or brightness. Such spreading is limited by partially delineated borders along which the illusory contours form. In these terms, there seems little reason for distinguishing between Rood's (1879) and von Bezold's (1874) assimilation effects and van Tuijl's (1975) neon spreading. The second appears to be an instance of the first without the partial borders that restrict its spread.

\section{REFERENCES}

DAY, R. H., \& JoRY, M. K. Subjective contours, visual acuity and line contrast. In J. C. Armington, J. E. Krauskopf, \&. R. Wooten (Eds.), Visual psychophysics: Its physiological basis. New York: Academic Press, 1979.

DAY, R. H., \& JorY, M. K. A note on a second stage in the formation of illusory contours. Perception \& Psychophysics, 1980, 27, 89-91.

DAY, R. H., \& KAgPEnczyK, R. T. Amodal completion as a basis for illusory contours. Perception \& Psychophysics, 1983, 33, 355-364. (a)
DAY, R. H., \& KASPE RCZYK, R. T. Illusory contours in line patterns with apparent depth due to either perspective or overlay. Perception, 1983, in press. (b)

Ehrenstein, W. Beitrage zur Ganzheits psychologischen Wahrnehmungslehre. Leipzig: Barth, 1942.

Frisey, J. P., \& Cla tworthy, J. L. Illusory contours: Curious cases of simultaneous brightness contrast? Perception, 1975, 4, 349-357.

GRE GORY, R. L. Cognitive contours. Nature, 1972, 238, 51-52.

Helson, H. Some factors and implications of color constancy. Journal of the Optical Society of America, 1943, 33, 555-557.

HeLson, H., \& JoY, V. L. Domains of lightness assimilation and contrast. Psychologische Beitrage, 1962, 6, 405-415.

Helson, H., \& Rohles, F. H. A quantitative study of the reversal of classical lightness contrast. American Journal of Psychology, 1959, 72, 530-538.

KanizsA, G. Margini quasi-percettivi in campi con stimolazione omogenea. Revista di Psicologia, 1955, 49, 7-30.

KanizsA, G. Subjective contours. Scientific American, 1976, 234, 48-52.

KanizsA, G. Organization in vision. New York: Praeger, 1979.

Kennedy, J. M. Subjective contours, contrast, and assimilation. In C. F. Nodine \& D. F. Fisher (Eds.), Perception and pictorial representation. New York: Praeger, 1979.

KorfKa, K. Principles of Gestalt psychology. New York: Harcourt Brace, 1935.

Newhall, S. M. The reversal of simultaneous brightness contrast. Journal of Experimental Psychology, 1942, 31, 393-409.

Redies, C., \& Spilluan, L. The neon color effect in the Ehrenstein illusion. Perception, 1981, 10, 667-681.

Rood, O. N. Modern chromatics. London: Kegan Paul, 1879.

Schumann, F. Einige Beobachtungen uber die Zusammenfassung von Gesichtseindrucken zu Einheiten. Psychologische Studien, 1904, 1, 1-32.

van TuIJl, H. F. J. M. A new visual illusion: Neonlike color spreading and complementary color induction between subjective contours. Acta Psychologica, 1975, 39, 441-445.

van TUiJl, H. F. J. M., \& DE WEERT, M. M. Sensory conditions for the occurrence of the neon spreading illusion. Perception, $1979,8,211-215$.

VAN TUiJl, H. F. J. M., \& Leeuwenbera, E. L. J. Neon color spreading and structural information measures. Perception \& Psychophysics, 1979, 25, 269-284.

VARIN, D. Fenomini di contrasto e diffusione chromatica nell' organizzazone spaziale del campo percettivo. Revista di Psychologica, 1971, 65, 101-128.

von Bezold, W. Die Farbenlehre [The theory of color] (S. R. Koehler, trans.). Boston: Prang, 1876.

Ware, C. Colored illusory triangles due to assimilation. Perception, 1980, 9, 103-107.

(Manuscript received July 19, 1983; accepted for publication August 3, 1983.) 